\title{
FEM ANALYSIS AND EXPERIMENTAL TESTS OF RIGID RISER HANGING SYSTEM
}

\author{
Artur Olszewski \\ Michał Wodtke \\ Gdańsk University of Technology, Poland, \\ Artur Wójcikowski \\ LOTOS Petrobaltic, Poland
}

\begin{abstract}
The article presents the analysis, project, and experimental examination of an original rigid riser for Coil Tubing Pipes. The principle of riser operation is based on the use of friction forces. The research included the FEM analysis of the designed riser, calculations of the required bolt tensions, and checking the effect of the clamping force on stress distribution in the pipeline. The results of computer simulation were verified on a specially designed test rig. The described riser design was implemented on the LOTOS Petrobaltic platform, thus eliminating the need for purchase and installation of expensive elastic risers.
\end{abstract}

Keywords: offshore engineering, riser hanging system, FEM simulations, experimental tests

\section{MOTIVATIONS AND PURPOSE OF WORK}

At the deposit B8 (the Baltic Sea), seawater injection has been used to increase and maintain the formation pressure, thus intensifying the output and increasing the recovery factor [5].

The reservoir fluid extracted from the deposit is replaced by specially prepared seawater. For this purpose, a system was built on the platform which prepares the seawater for injection. Initially, the seawater is purified: solid impurities are removed mechanically and oxygen - chemically. Then the corrosion inhibitor is added to protect the injection installation against corrosion. Places of injection of the specially prepared seawater to the deposit are equipped with dedicated high-pressure injection heads, situated on the seabed at the drilled injection wells. The heads are connected with the surface part of the system via steel pipelines of Coil Tubing Pipe (CTP) type (Fig. 1).

Five pipeline segments of this type were laid on the deposit B8. Before the injection, they had to be connected with the injection system on the platform. For this purpose, all pipeline ends were placed in specially designed and manufactured suspension systems, so-called CTP risers, which were installed on the side of the LOTOS Petrobaltic platform. The idea of this type of suspension system for CTP pipelines was developed at LOTOS Petrobaltic and initially used on the Baltic Beta platform to connect the seawater injection system with the injection head situated on the seabed.

The use of CTP risers brought significant savings, eliminating the need for purchase and installation of elastic risers, among other effects. 
The article describes the design and tests of the original CTP pipe riser which can be safely fixed to the platform hull side. This goal was achieved using 3D CAD, computer FEM simulation, and experimental prototype tests.

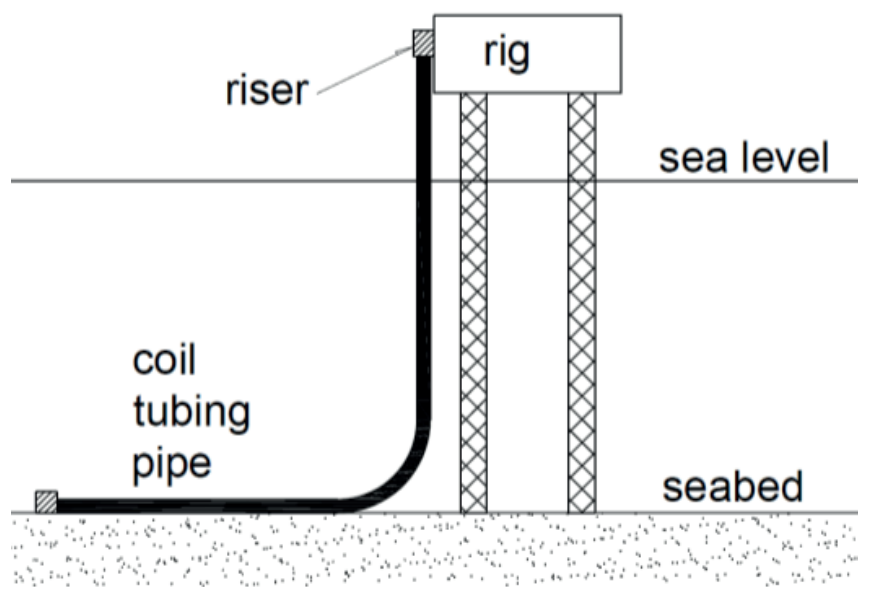

Fig. 1. Scheme of injection pipe riser placement

\section{PROJECT ASSUMPTIONS}

The following assumptions were defined before starting the project:

1. The riser cannot interfere into the pipe structure (its welding to the CTP pipe and machining are not permitted), due to extremely high stresses in CTP pipes.

2. The riser should generate the minimum possible load for the weld connecting the CTP pipe with the collar.

3. The possibility to control the vertical position of the pipe during assembly is required.

4. The approximate weight of the suspended pipe filled with water is $19 \mathrm{kN}$.

5. The riser should have the ability for pipe fixing also when the pipe axis leans from the vertical.

6. The riser should provide opportunities for CTP pipe control at places where the maximum pipe stresses occur.

Tab. 1. Data for CTP pipe suspension on Petrobaltic platform

\begin{tabular}{|l|l|}
\hline OD - outer diameter of steel part (4") & $101,6 \mathrm{~mm}$ \\
\hline Outer diameter with protective insulation & $105,26 \mathrm{~mm}$ \\
\hline ID - inner diameter & $86,36 \mathrm{~mm}$ \\
\hline WT - wall thickness (0,3") & $7,62 \mathrm{~mm}$ \\
\hline Mechanical properties & $\operatorname{Re} 483 \mathrm{MPa}, \mathrm{Rm} 552 \mathrm{MPa}$ \\
\hline Internal test pressure & $1,05 \times 33 \mathrm{MPa}$ \\
\hline $\begin{array}{l}\text { Nominal weight (mass) } \\
\text { Expected maximum operating seawater } \\
\text { pressure }\end{array}$ & $17,64[\mathrm{~kg} / \mathrm{m}]$ \\
\hline $\begin{array}{l}\text { Expected current operating seawater } \\
\text { pressure }\end{array}$ & $30 \mathrm{MPa}$ \\
\hline
\end{tabular}

The designed method of CTP pipe suspension is shown in Fig. 2. The principle of operation of the designed riser consist in the use of friction collet clamp which makes use of friction forces to keep the CTP pipe at a given position (Fig. 2). The CTP injection pipe is fixed in a collet clamp which is clamped with force F. The pipe weight is counterbalanced by friction forces on the contact surface between the pipe and the clamping jaws. The collet clamp is fixed with screws to a stable foundation welded to the platform hull. The upper end of the pipe has a welded collar which enables connecting it, by means of screws, to an elastic joint mounted on the platform and connected to the water injection pump. Thanks to this solution, the weld which joints the collar with the CTP pipe is not loaded with the bending moment resulting from sea undulation, nor with the axial force resulting from the weight of the suspended pipe. High pressure of the injection water in the pipe is the source of high reduced stresses, which can reach about $300 \mathrm{MPa}$, hence direct suspension of the pipe by upper collar is not possible as it would cause additional stresses in the weld, thus significantly reducing its fatigue life.

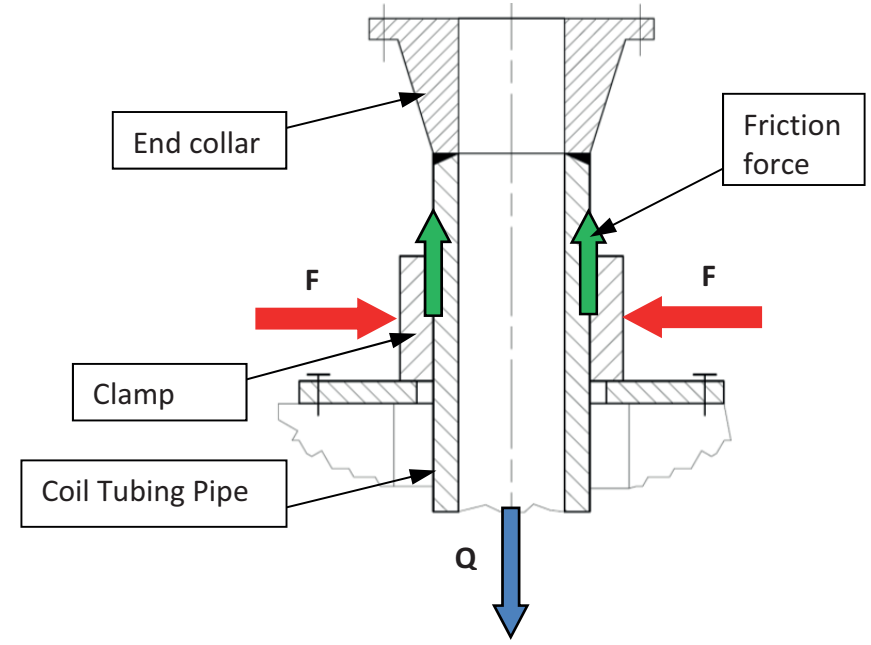

Fig. 2. CTP pipe suspension making use of collet clamp (description in the text)

\section{STRUCTURE OF THE DESIGNED RISER}

A general view of the designed collet riser (without foundation) is given in Fig. 3. Basic elements of the riser include: the collet clamp (two jaws) with tension bolts and disc springs, the split foundation ball for the collet clamp, and the split lower sleeve fixed to the foundation ball. 


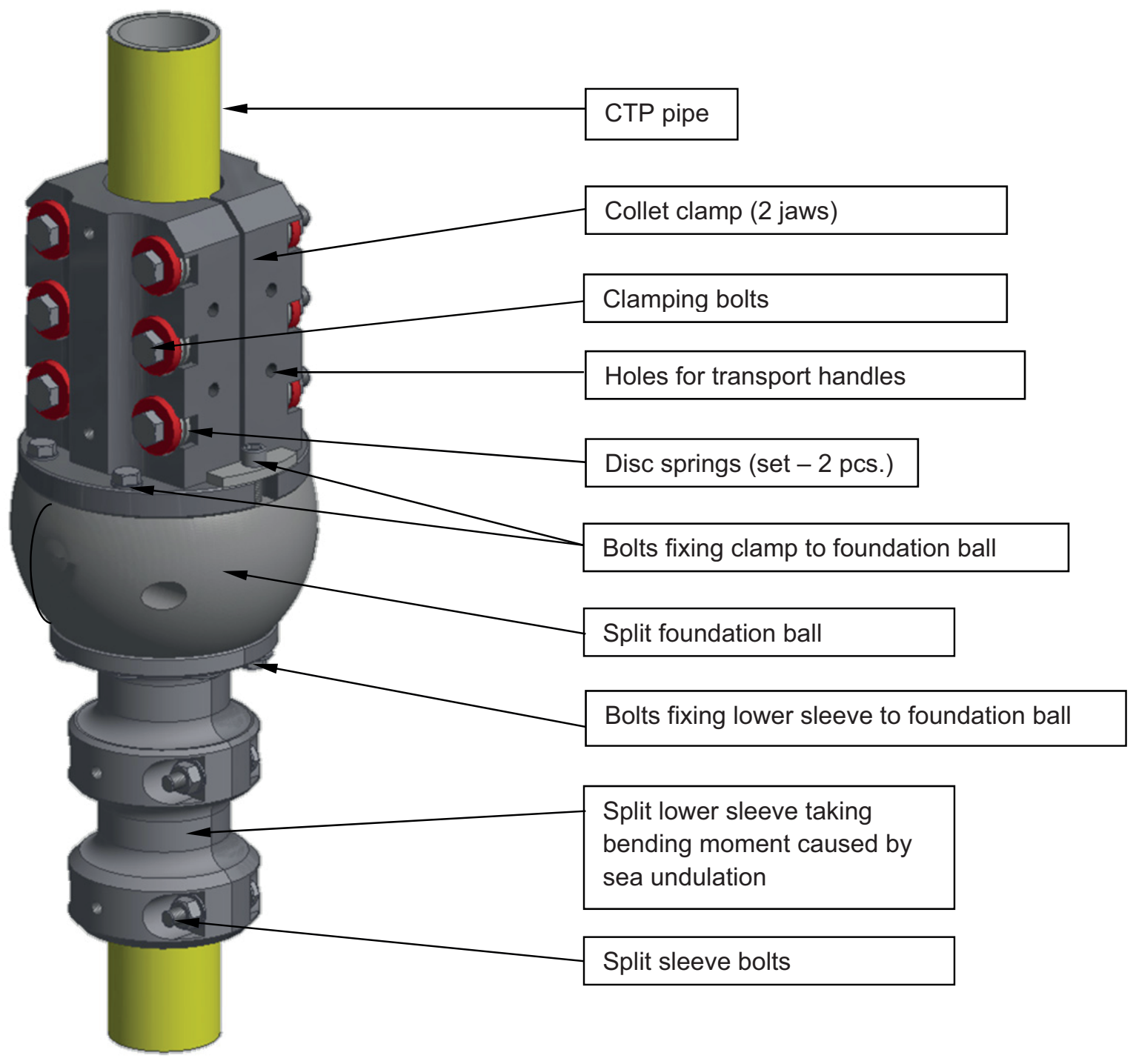

Fig. 3. Structure of collet riser for CTP pipe suspension

The main characteristic properties of the new design can be outlined as follows:

- The CTP pipe is kept using friction forces between the split collet clamp (jaws) and the pipe.

- The friction forces are generated by clamping of the split clamp on the pipe, which is executed by six M16 (optionally M20) bolts. The maximum clamping force of the jaws exceeds $600 \mathrm{kN}$ (for six M20 bolts, class 8.8). The bolts can be tensioned with different moment, thus ensuring proper adjustment of the clamping force.

- Sets of disc springs were used to minimise the effect of clamping force reduction caused by insulation escape from the clamp or its flow (in a relatively long time) [6]. During the assembly, the disc spring sets buckle by about $4,8 \mathrm{~mm}$ per each bolt, thanks to which decreasing the distance between the clamping jaws by even as much as several millimetres does not lead to significant decrease of the clamping force.

- The disc springs are placed in special sockets equipped with measuring windows to control the preliminary tension and technical condition of the springs.

- The designed riser does not load the pipe weld. Moreover, it has the ability to control vertical position of the pipe during assembly, which significantly increases the fatigue life of the weld joining the pipe with the collar $[1,11]$.

- The collet clamp is fixed to the split ball, which enables assembly of the pipe when it is leaned from the vertical. After the assembly, the ball does not rotate in the foundation - it is protected against rotation by ring clamps, fixed with bolts to the ball.

- A split stiffening sleeve is fixed to the bottom part of the ball. Its task is to carry the bending moment caused by sea undulation. The stiffening sleeve has a rounded cone shaped inner hole to decrease the local stress 
concentrations caused by bending. The sleeve can be periodically dismantled to check technical condition of the CTP pipe segment situated inside it.

\section{RESULTS OF CALCULATIONS OF BOLTS AND DISC SPRINGS FOR CTP PIPE COLLET CLAMP}

Tab. 2 collates technical data of the used disc springs. Depending on the applied bolts, the springs with inner hole of $\varnothing 17$ or $\varnothing 20$ are to be mounted.

The table also contains the calculated maximal tightening torques and corresponding axial forces in the bolts.

Tab. 2. Technical parameters of the selected disc spring and selected method of spring set assembly (inner hole diameter $17 \mathrm{~mm}$ ) [6]

\begin{tabular}{|c|c|c|c|c|c|}
\hline $\begin{array}{c}\text { Di - inner } \\
\text { diameter }\end{array}$ & $\begin{array}{c}\text { Do- outer } \\
\text { diameter }\end{array}$ & $\begin{array}{c}\text { Lo - free } \\
\text { length }\end{array}$ & T-thickness & $\begin{array}{c}\text { Maximal } \\
\text { deflection }\end{array}$ & $\begin{array}{c}\text { Force at } \\
\text { maximal } \\
\text { deflection }\end{array}$ \\
\hline $17 \mathrm{~mm}$ & $42 \mathrm{~mm}$ & $6,2 \mathrm{~mm}$ & $4 \mathrm{~mm}$ & $1,2 \mathrm{~mm}$ & $58 \mathrm{kN}$ \\
\hline
\end{tabular}
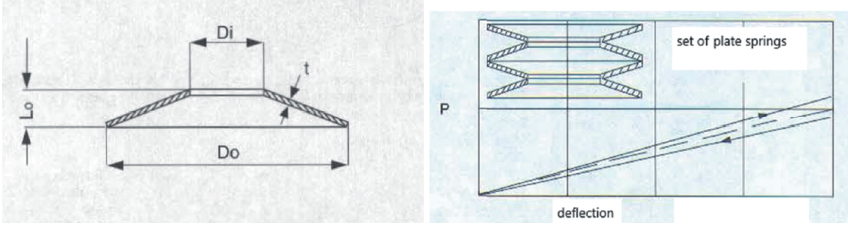

Tab. 3. Calculated elongation and axial force in M16 bolt as functions of disc spring tightening torque

\begin{tabular}{|c|c|c|c|c|}
\hline $\begin{array}{c}\text { Bolt M16 } \\
\text { Class } 8.8 \\
\mu=0,14 \\
\mathrm{D}=22 \mathrm{~mm} \\
\mathrm{~L}=150 \mathrm{~mm} 1\end{array}$ & $\begin{array}{c}\text { Tightening } \\
\text { torque }\end{array}$ & $\begin{array}{c}\text { Axial force } \\
\text { in bolt }\end{array}$ & $\begin{array}{c}\text { Reduced } \\
\text { stress in bolt }\end{array}$ & $\begin{array}{c}\text { Bolt } \\
\text { elongation }\end{array}$ \\
\hline & $200 \mathrm{Nm}$ & $65,4 \mathrm{kN}$ & $605 \mathrm{MPa}$ & $0,33 \mathrm{~mm}$ \\
\hline & $100 \mathrm{Nm}$ & $32,7 \mathrm{kN}$ & $302 \mathrm{MPa}$ & $0,16 \mathrm{~mm}$ \\
\hline
\end{tabular}

\section{COMPURTER SIMULATION OF RISER BEHAVIOUR DURING ASSEMBLY AND WORK}

This section presents results of simulation calculations reflecting the behaviour of the riser/pipe arrangement during assembly and work. The calculations made use of the FEM method, frequently applied to analyse issues of this type $[2,3,4,7-9]$.

The material data were assumed in accordance with the catalogue card of CTP pipes, (the material S355J2G3 was assumed for the clamp). The friction coefficient was assumed constant and equal to $\mu=0,1$. This value was assessed based on simple measurements of resistance to motion, done using a dynamometer. In the calculations, the contribution of the outer pipe insulation layer made of plastic was neglected, as no reliable physical data were available for this material and its thickness was relatively small (only steel pipe without insulation was simulated).

\section{MODEL AND ANALYSED LOAD CASES}

The computer model precisely mapped the shape of he collet clamp (Fig. 4). The diameter of the hole for the pipe was larger by $2 \mathrm{~mm}$ than the outer diameter of the steel pipe part. The length of the clamp was $290 \mathrm{~mm}$, and the collar diameter was $275 \mathrm{~mm}$. On the contact surface, contact elements were applied to simulate pipe slip with respect to the clamp. The used FEM grid is shown in Fig. 5.

The calculations were performed for two load stages. In the first stage, the behaviour of the clamp after assembly on the pipe (i.e. before creating internal pressure) was simulated. The maximal axial force in each bolt was $60 \mathrm{kN}(360 \mathrm{kN}$ in total) and was applied to each individual bolt socket. In the second stage, the assembled clamp was loaded with additional internal pressure $(30 \mathrm{MPa})$ and then with the axial force, until the slip between the pipe and the clamp was recorded. By this way, the limiting value of the axial force which can be applied to the pipe without its slip from the riser was assessed.

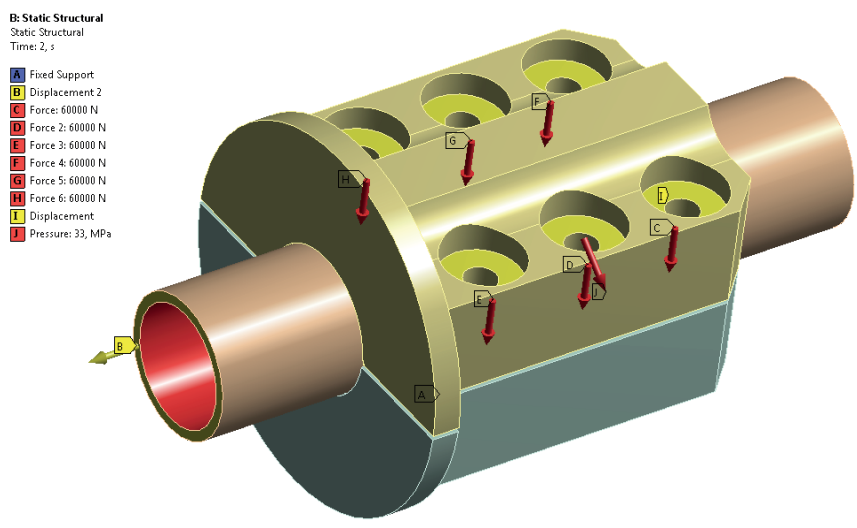

Fig. 4. Boundary conditions for the model. Loading forces resulting from bolt tension, along with internal pressure in the pipe and axial force acting on the pipe

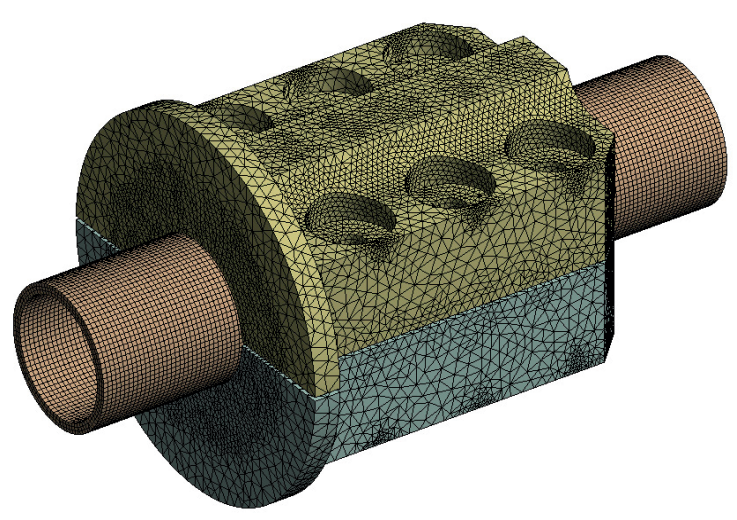

Fig. 5. Computer model of the clamp with pipe segment, and the marked FEM grid 


\section{SELECTED RESULTS OF CALCULATIONS}

Selected results of calculations are shown in Fig. 6 through Fig. 9.

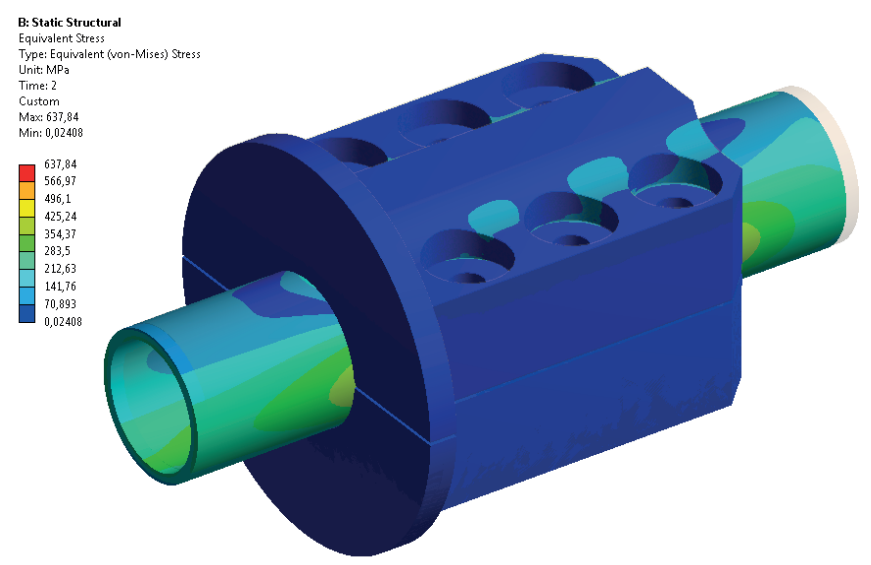

Fig. 6. Reduced stresses [MPa] - loading with axial force and internal pressure $p=30 \mathrm{MPa}$. Preliminary bolt tension force $60 \mathrm{kN}$

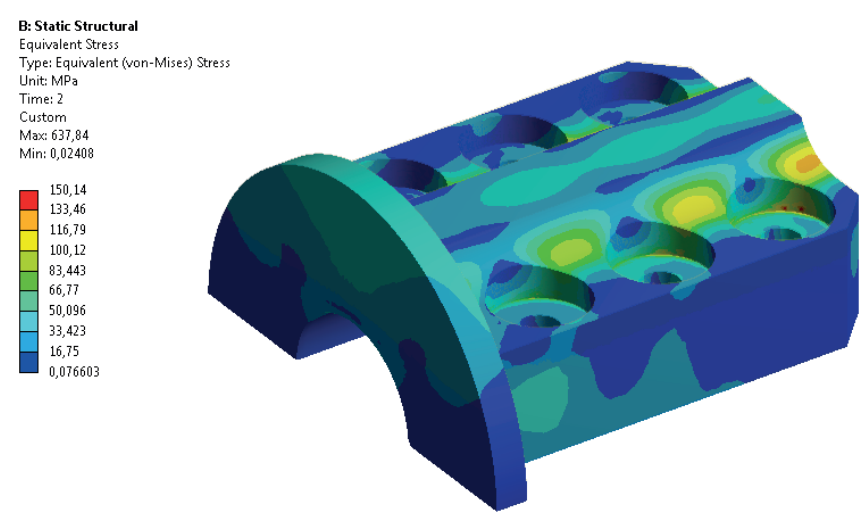

Fig. 7. Reduced stresses in the clamp [MPa] - loading with axial force and internal pressure. Preliminary bolt tension force $60 \mathrm{kN}$

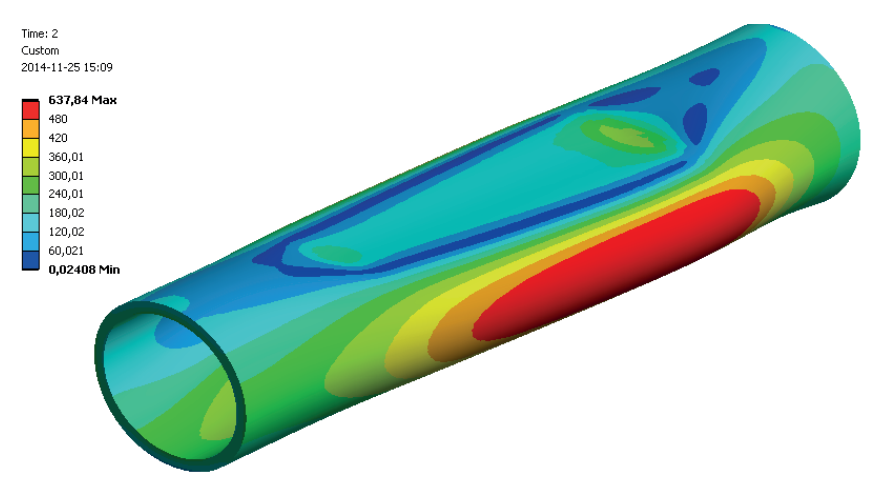

Fig. 8. Reduced stresses in the pipe [MPa] (red colour-above Re) - loading with axial force and internal pressure. Preliminary bolt tension force $60 \mathrm{kN}$

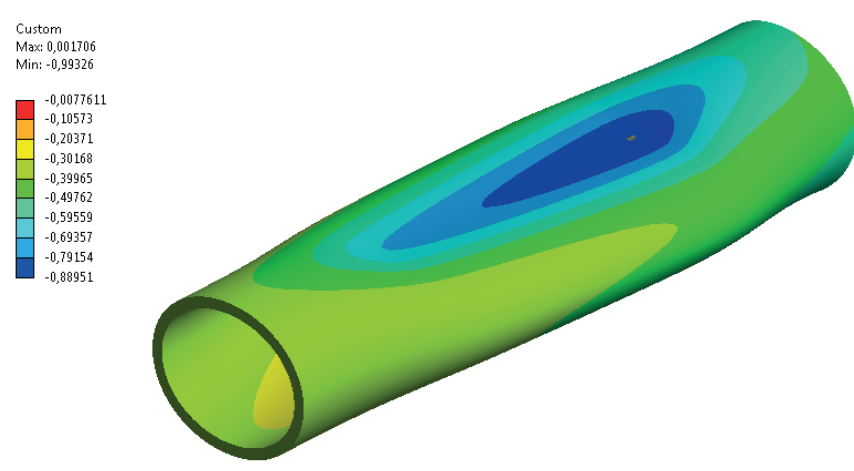

Fig. 9. Pipe deformation [mm] - loading with axial force and internal pressure. Preliminary bolt tension force $60 \mathrm{kN}$

The analysis of calculation results has proved that the designed riser is able to carry the assumed axial force of $19 \mathrm{kN}$ (nominal load) using only friction forces. The simulation has revealed that for the assumed friction coefficient equal to 0,1 and the absence of internal pressure, clamping the pipe with the force of $360 \mathrm{kN}$ enables loading it with the maximal theoretical axial force equal to $87 \mathrm{kN}$. When additional internal pressure equal to $30 \mathrm{MPa}$ is applied to the riser already clamped with the force of $360 \mathrm{kN}$, the maximal theoretical axial force increases to $94 \mathrm{kN}$, as a result of the increased pressure force between the pipe wall and the riser. The simulations have also shown favourable distribution of deformations of the clamped pipe. After clamping it in the riser, the pipe takes a conical shape in the clamping area, which additionally increases the permissible axial force to be carried by the riser. Clamping the pipe with the force of $360 \mathrm{kN}$ may result in the appearance of small and local yielding of pipe wall in the vicinity of its outer surface.

\section{EXPERIMENTAL EXAMINATION}

Due to the lack of material data, the behaviour of the thin protecting layer of the pipe was not modelled in computer simulations. Moreover, the constant value of friction coefficient on the contact surface between the pipe and the collet clamp was assumed a priori.

Since effective simulation of the effect of the insulating layer on forces carried by the riser was not possible, a decision was made to perform experimental tests to determine the optimal clamping force. When it is too large, the clamping force might damage the insulating layer, while too small a value would lead to its slow slip from the clamp. The tests were performed after mounting a real riser on a segment of CTP pipe intended for assembly. Since correct operation of the riser is of high importance for the entire installation, a decision was made to perform additional experimental (checking) tests before its installation on the extraction platform. These experimental tests aimed at verifying the correctness of the developed computer model and determining the optimal value of the bolt tightening torque to ensure sound pipe clamping without insulation damage. 


\section{PROJECT AND CONSTRUCTION OF TEST RIG}

To examine the functionality of the designed collet riser, a special test rig was designed and built. This test rig simulated loading the pipe with the axial force equivalent to the weight of a real pipe filled with injection water. During the pipe operation, the axial force acting on the pipe is approximately equal to $20 \mathrm{kN}$ (for a pipe segment of over $100 \mathrm{~m}$ in length).

\section{TEST METHODOLOGY}

The following parameters were selected for recording during the measurements:

- Pipe displacement along vertical axis [m]

- Axial force loading the pipe $[\mathrm{N}]$

- Tightening torque applied to M16 bolts tightening the collet clamp [Nm]

The constructed test rig which simulated loading of a CTP pipe fixed in the riser is shown in Fig. 10. It consists of a steel supporting frame, a hydraulic cylinder with force manometer, and a manual hydraulic pump.

Before basic tests, the hydraulic system was calibrated using an electronic force transducer (Fig. 10) mounted on the piston rod end. The performed measurements made the basis for working out the diagram of real axial force generated by the transducer as a function of the oil pressure shown by the manometer mounted on the pump.

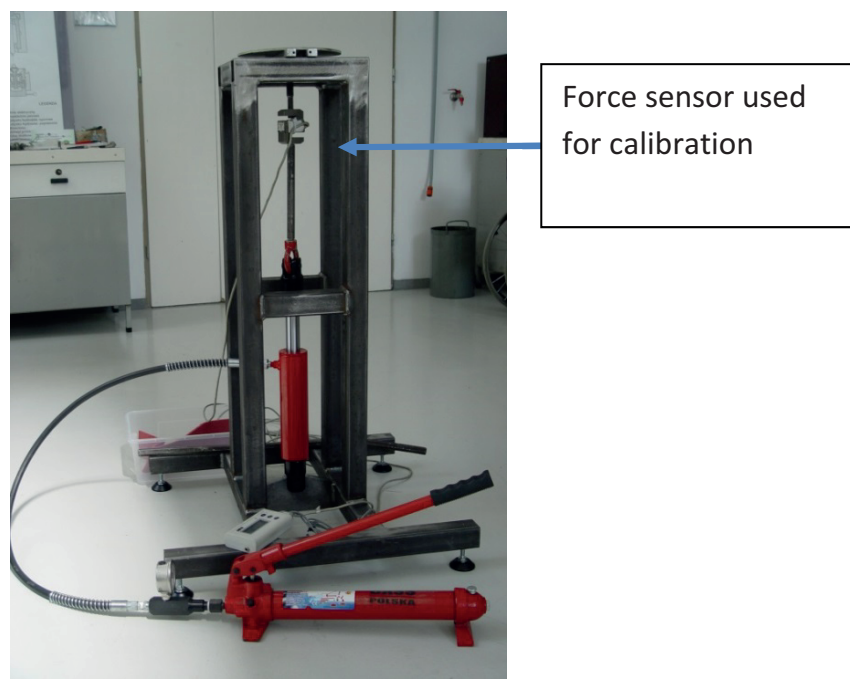

Fig. 10. General view of the test rig during hydraulic cylinder calibration

After the calibration, the collet riser with clamped CTP pipe was mounted on the test rig (Fig. 11). Additionally, a dial indicator was installed to measure axial pipe displacement with respect to the collet clamp under the action of load (Fig. 11).

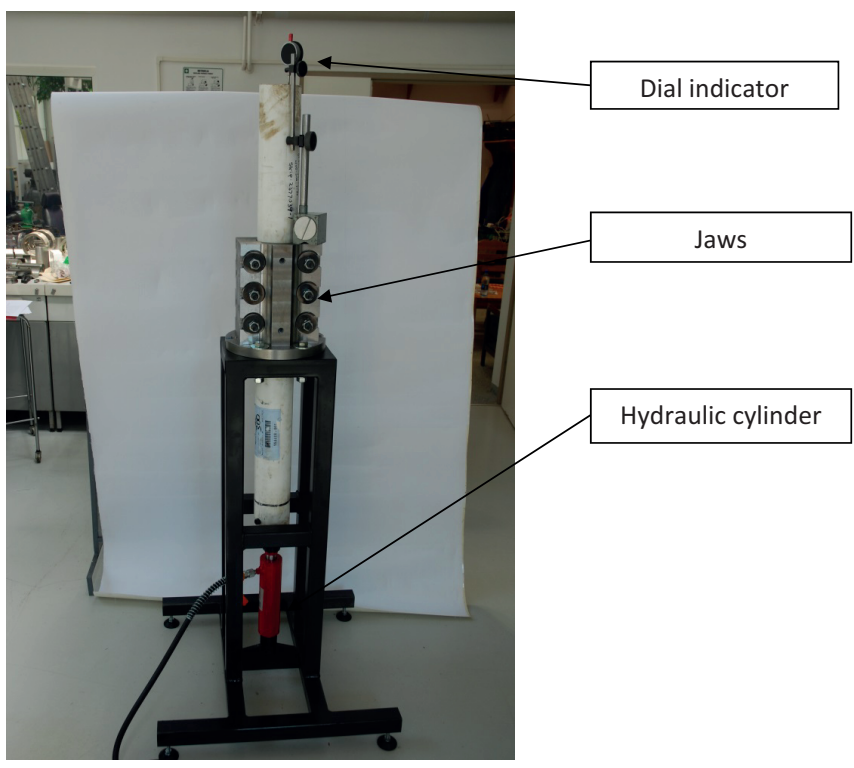

Fig. 11. Test rig with hydraulic cylinder and dial indicator

This dial indicator, with $1 \mu \mathrm{m}$ resolution, was mounted on a stable magnetic tripod situated on the upper layer of the collet clamp. In this way the effect of supporting frame deflection on the result of measurement of pipe displacement with respect to the clamp was eliminated. After preliminary examination of test rig operation, basic tests of the designed riser were performed.

\section{RESULTS OF EXPERIMENTAL TESTS}

Tab.4 shows individual test stages, along with the recorded results of pipe displacement with respect to the collet clamp.

Tab. 4. Test stages and recorded pipe displacements

\begin{tabular}{|c|c|c|c|c|c|}
\hline 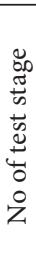 & 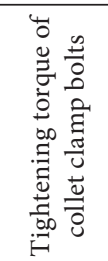 & 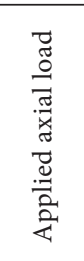 & 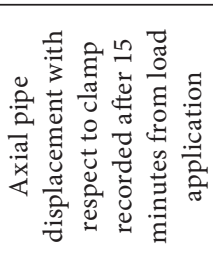 & 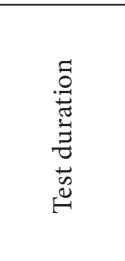 & 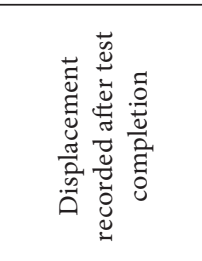 \\
\hline 1. & $100 \mathrm{Nm}$ & $24 \mathrm{kN}$ & $7 \mu \mathrm{m}$ & 48 hours & $11 \mu \mathrm{m}$ \\
\hline 2. & $200 \mathrm{Nm}$ & $24 \mathrm{kN}$ & no displacement & 48 hours & no displacement \\
\hline 3. & $200 \mathrm{Nm}$ & $60 \mathrm{kN}$ & no displacement & 72 hours & no displacement \\
\hline 4. & $200 \mathrm{Nm}$ & $75 \mathrm{kN}$ & no displacement & 168 hours & no displacement \\
\hline
\end{tabular}

Once the maximum load of $75 \mathrm{kN}$ was reached, which corresponded to more than 3,5-fold load resulting from the weight of pipe filled with water, the test was stopped.

\section{MEASUREMENTS AND INSPECTIONS OF DISC SPRINGS}

After a series of tests, the riser was removed from the rig, the clamp tightening bolts unloosed, and the measurements 
and inspections of the disc springs and the pipe insulation layer were performed.

The height of the set of disc springs was measured before and after the tests. The initial height of all sets was equal to $10,5 \pm 0,2 \mathrm{~mm}$. The results of disc spring set measurements after the tests are collated in Tab. 5 .

Tab. 5. Measured height of disc spring sets after tests

\begin{tabular}{|c|c|c|}
\hline Bolt no. & $\begin{array}{c}\text { Height of set from the bolt } \\
\text { head side }[\mathrm{mm}]\end{array}$ & $\begin{array}{c}\text { Height of set from the nut } \\
\text { side }[\mathrm{mm}]\end{array}$ \\
\hline 1 & 9 & 9,25 \\
\hline 2 & 9,3 & 9,45 \\
\hline 3 & 9,15 & 9 \\
\hline 4 & 8,73 & 8,67 \\
\hline 5 & 9,12 & 8,87 \\
\hline 6 & 9,23 & 9,23 \\
\hline
\end{tabular}

Permanent (plastic) deformation of springs loaded with force of $75 \mathrm{kN}$ did not exceed $20 \%$ of the nominal set height before assembly.

\section{ASSESSING CONDITION OF THE CTO PIPE INSULATING LAYER SURFACE AFTER TESTS}

After completing all measurements, the condition of the insulating layer surface was inspected. No significant deformations were detected, only the outer diameter of the pipe with layer decreased locally by about $0,05 \mathrm{~mm}$. Neither traces of material cohesiveness loss of the insulation layer, nor cracks, scuffs, or material losses were detected (Fig.12).

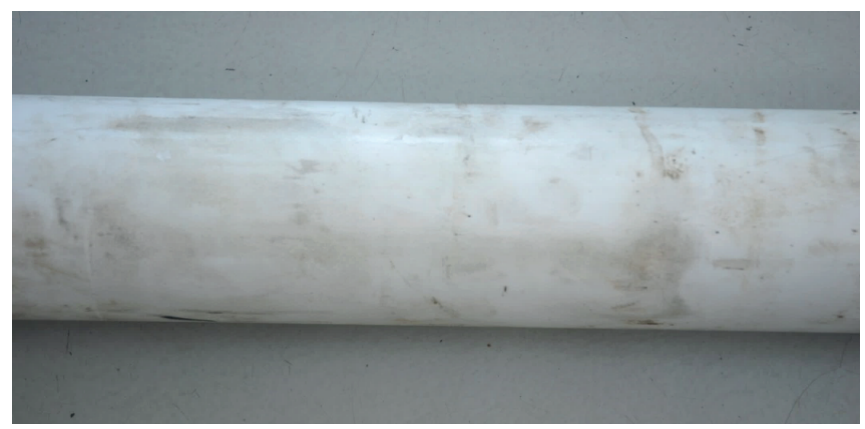

Fig.12. Condition of CTP pipe protection layer after tests - no outer layer damages

\section{CONCLUSIONS}

- The theoretical and experimental examination has shown that the designed riser meets all adopted design assumptions, which proves its serviceability.

- The computer analysis of the pipe clamp has shown that there is a possibility to carry the CTP pipe weight by friction forces (without the use of form-fitting connection).
- The simulations have shown that for the friction coefficient equal to 0,1 - as assumed in the calculations - and the absence of internal pressure, clamping the pipe with the force of $360 \mathrm{kN}$ enables loading it with the maximal theoretical axial force equal to $87 \mathrm{kN}$. When additional internal pressure equal to $30 \mathrm{MPa}$ is applied to the riser already clamped with the force of $360 \mathrm{kN}$, the maximal theoretical axial force increases to $94 \mathrm{kN}$, as a result of the increased pressure force between the pipe wall and the riser.

- The simulations have revealed favourable distribution of deformations of the clamped pipe. After clamping it in the riser, the pipe takes a conical shape in the clamping area, which additionally increases the permissible axial force to be carried by the riser. Clamping the pipe with the force of $360 \mathrm{kN}$ may result in the appearance of small yielding of pipe wall in the vicinity of its outer surface. This effect is local in nature and is not dangerous.

- The use of springs ensures maintaining the required clamping force even if the insulation layer partially flows, or the pipe changes the shape.

- Since effective simulation of the effect of the insulating layer on forces carried by the riser was not possible, additional experimental tests were performed to determine the optimal clamping force. When it is too large, the clamping force might damage the insulating layer, while too small a value would lead to its slow slip from the clamp.

- The performed experimental tests have confirmed correct operation of the riser, even at over 3-fold higher overload. The recorded pipe displacements in the clamp are close to measurement errors, therefore it should be stated that the pipe does not move in the clamp, even after a longer time of axial load action.

- The riser does not cause damage to the outer pipe layer.

- Based on the performed tests, the optimal tightening torque for collet clamp bolts was assessed as equal to $180 \mathrm{Nm}$.

- The performed experimental test made the basis for working out a manual for collet clamp bolt assembly, tightening and control.

\section{SUMMARY}

After completing the tests, marine versions of the riser which are resistant to the action of marine environment were manufactured and installed on platforms in 2014.

Fig. 12 shows the risers mounted on the LOTOS Petrobaltic platform. 


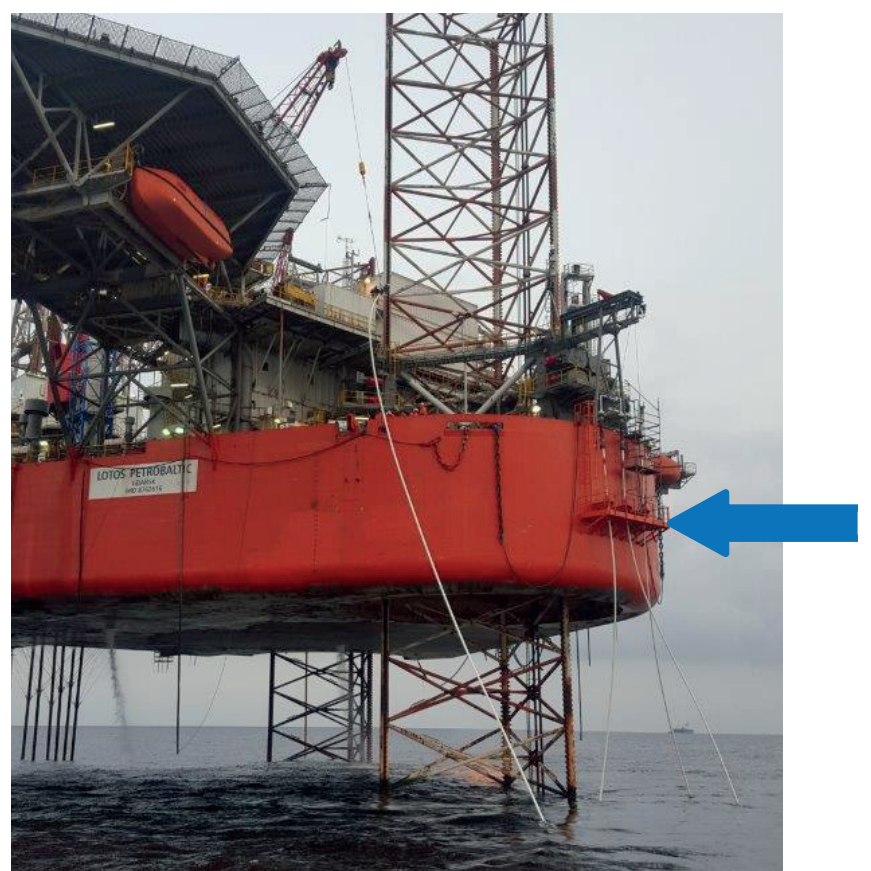

Fig. 12. Risers mounted on LOTOS Petrobaltic platform, along with CTP injection pipes

\section{BIBLIOGRAPHY}

1. Jakubowski M.: Corrosion Fatigue Crack Propagation Rate Characteristics for Weldable Ship and Offshore Steels with Regard to the Influence of Loading Frequency and Saltwater Temperature. Polish Maritime Research, Volume 24, Issue 1. Pages 88-99.

2. Litwin W., Olszewski A.: Water-Lubricated Sintered Bronze Journal Bearings-Theoretical and Experimental Research. Tribology Transactions. Vol. 57, nr 12014 , s.114-122.

3. Merahn., Zayera., Shuai, B.A.: Finite element evaluation of clearance effect on tube-to-tubesheet joint strength, International Journal of Pressure Vessels and piping. Vol. 80, no, 12, pp. 579-585, 2003.

4. Patel M.H, Sarohia S.: Finite-element analysis of the marine riser. Engineering Structures. Volume 6, Issue 3, July 1984, Pages 175-184.

5. Ramakrishnan T. V.: Offshore Engineering. Gene-Tech Books, 2008. ISBN 8189729802.

6. Disc springs, design recommendations (in Polish). Norm DIN 2093.

7. Wang, Y., Xu, W., Li, S., Zhang, H.: The Drilling Tool Against Expiration Technology of Power slip Clamp
Area, Drilling \& Production Technology, Vol. 29, no. 3, pp. 113-115, 2006.

8. Wodtke M., Olszewski A., Wasilczuk M.: Application of the fluid-structure interaction technique for the analysis of hydrodynamic lubrication problems. Proceedings of the Institution of Mechanical Engineers Part J-Journal of Engineering Tribology 2008. Vol. 227, nr 8. pp. 888-897.

9. www.ansys.com.

10. Zhuo Wang, Bo Zhang, Tao Wang : ANALYSIS AND EXPERIMENTS ON SEA LOAD AND FASTENED MECHANICS ON PIPE CLAMPS. Polish Maritime Research. Special Issue 2017 S2 (94) 2017 Vol. 24; pp. 74-80.

11. Vázquez J., Navarro C., Dominguez J. (2009). On the estimation of fatigue life in notches differentiating the phases of crack initiation and propagation. Fatigue Fract. Engng Mater. Struct., 33, 22-36.

\section{CONTACT WITH THE AUTHORS}

\author{
Artur Olszewski \\ e-mail:aolszews@pg.edu.pl
}

Gdańsk University of Technology Faculty of Mechanical Engineering

11/12 Narutowicza St. 80-233 Gdańsk

POLAND

\section{Michał Wodtke}

Gdańsk University of Technology Faculty of Mechanical Engineering

11/12 Narutowicza St. 80-233 Gdańsk

Poland

\section{Artur Wójcikowski}

LOTOS Petrobaltic Poland 